\title{
Gradhiva
}

GRADHIV

Revue d'anthropologie et d'histoire des arts

$2 \mid 2005$

Autour de Lucien Sebag

\section{Le voyage au ciel}

\section{Lucien Sebag}

Salvatore D'Onofrio (éd.)

\section{CpenEdition}

Journals

Édition électronique

URL : http://journals.openedition.org/gradhiva/515

DOI : $10.4000 /$ gradhiva. 515

ISSN : 1760-849X

Éditeur

Musée du quai Branly Jacques Chirac

Édition imprimée

Date de publication : 1 novembre 2005

Pagination : 136-137

ISBN : 2-915-133-10-7

ISSN : 0764-8928

\section{Référence électronique}

Lucien Sebag, "Le voyage au ciel », Gradhiva [En ligne], 2 | 2005, mis en ligne le 09 décembre 2008,

consulté le 15 septembre 2020. URL : http://journals.openedition.org/gradhiva/515

Ce document a été généré automatiquement le 15 septembre 2020.

(C) musée du quai Branly 


\section{Le voyage au ciel}

\section{Lucien Sebag}

Salvatore D'Onofrio (éd.)

\section{NOTE DE L'ÉDITEUR}

Page manuscrite d'un mythe recueilli à Tobité, en Bolivie : le « voyage au ciel » du chamane. Il est classé comme le dernier des mythes recueillis par Sebag. Les mythes ayorés racontent les événements qui eurent lieu au commencement du monde, « quand tout était ayoré » (personne, homme), selon un incipit souvent utilisé. Ils racontent en particulier les métamorphoses subies par les êtres originels ayorés qui sont devenus les autres êtres, les plantes, les animaux et même des concepts abstraits comme le courage. Il n'y a que le chamane (ou le guerrier) qui peut actualiser le temps des origines par ses pouvoirs et son accès exclusif au tabac, aux voix ou à des objets magiques comme le bâton qui, en se transformant en ailes, lui permet le « voyage au ciel ». C'est la maîtrise des relations entraînées par ces métamorphoses, assumées courageusement jusqu'au bout, qui permet au chamane d'assurer la médiation entre les humains et les « animaux célestes » comme l'oiseau Pakatiarhai.

S. D'O. 
Le chamane Acui (clan Possoahá) fumant sa pipe, Maria Auxiliadora, haut Paraguay, octobrenovembre 1963.

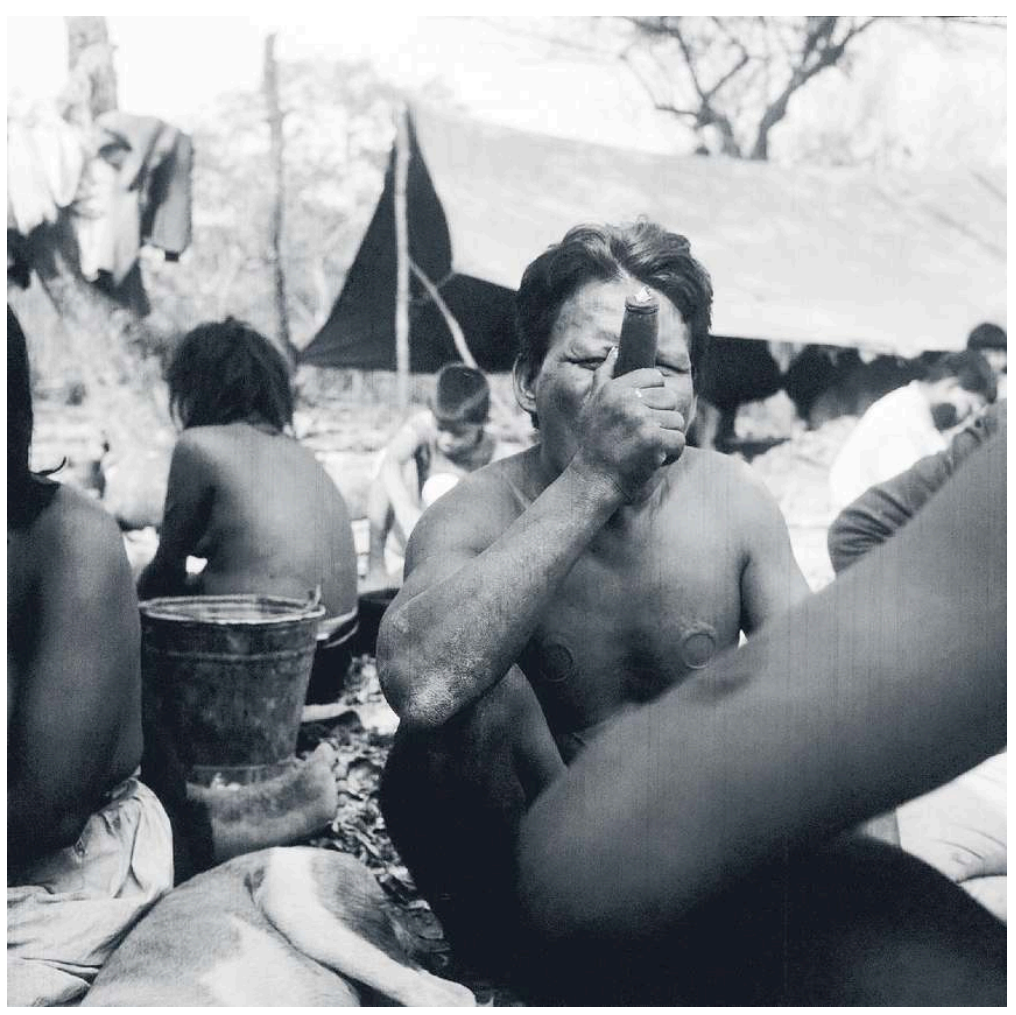

(C) Laboratoire d'anthropologie sociale, fonds Sebag

Page manuscrite d'un des cahiers de Sebag reproduisant le « voyage au ciel ».

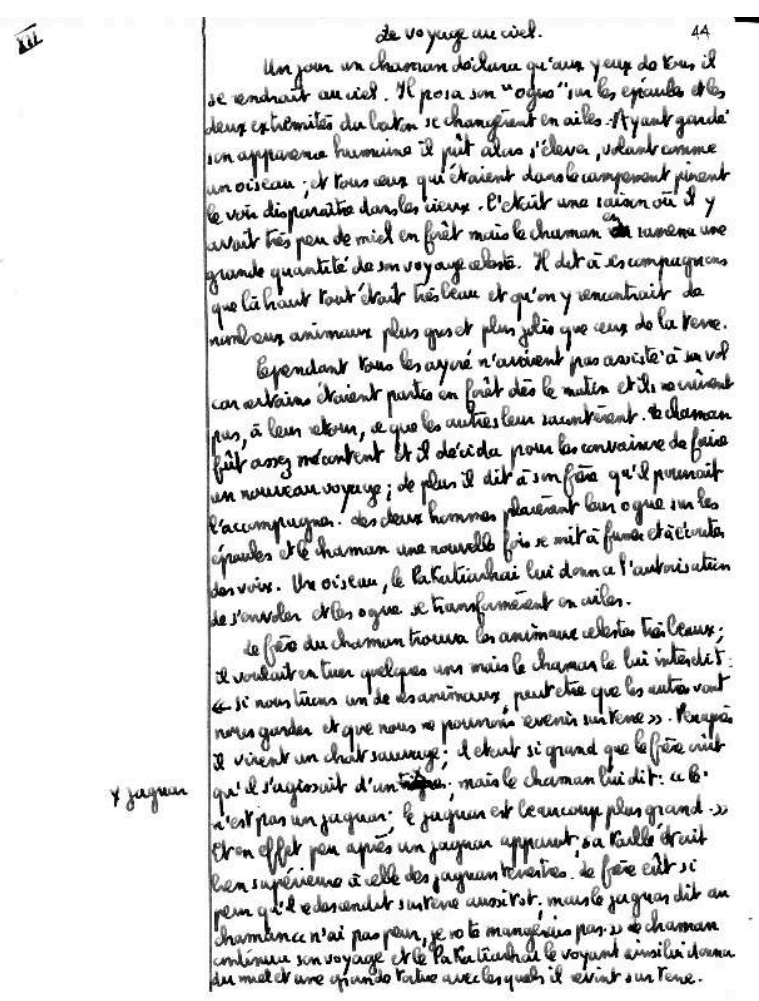

(c) Laboratoire d'anthropologie sociale, fonds Sebag 